\title{
CRESCIMENTO DE MINIRREBOLOS DE CANA-DE-AÇÚCAR SOB DOSES DE ÁCIDO INDOLBUTÍRICO E ÁCIDO GIBERÉLICO
}

\section{GROWTH OF SUGARCANE MINIRREBOLS UNDER DOSES OF INDOLBUTYRIC ACID AND GIBERELIC ACID}

\author{
Leidiane dos Santos Lucas ${ }^{1}$; Joseanny Cardoso da Silva Pereira ${ }^{2}$; Mirelly Martins da Silva ${ }^{3}$; Millena \\ Yorrâna Oliveira Silva ${ }^{3}$; Doralice Ferreira Alves ${ }^{3}$.
}

${ }^{1}$ Discente do Curso de Agronomia Faculdade Evangélica de Goianésia - e-mail: leidianesantos0303@gmail.com.

${ }^{2}$ Docente do Curso de Agronomia pesquisador Faculdade Evangélica de Goianésia.

${ }^{3}$ Discente do Curso de Agronomia Faculdade Evangélica de Goianésia.

\section{Info}

Recebido: 01/2019

Publicado: 06/2019

ISSN: 2595-6906

\section{Palavras-Chave}

SaccharumofficinarumL.Enraizament

o.Brotação.Reguladores de

Keywords:

Saccharum officinarum L. Rooting.

Sprouting. Growth regulators. crescimento.

\begin{abstract}
Resumo
A adoção doplantio mecanizado da cana-de-açúcar causou o aumento do número de falhas no plantio, o que acarretou prejuízos na produtividade. Devido a isso, o Programa Cana, do Instituto Agronômico de Campinas (IAC) desenvolveu o sistema de mudas pré-brotadas (MPB) com o objetivo de diminuir o volume de mudas e falhas, além de permitir maior controle na qualidade, tanto para controle de pragas e doenças quanto para uniformidade do canavial.No entanto, a capacidade de desenvolvimento da gema e do sistema radicular do minirrebolo é variável com a variedade. Dessa forma, o uso de reguladores vegetais pode induzir o desenvolvimento do minirrebolo, como o ácido giberélico, que influencia, principalmente, no alongamento da parte aérea e o ácido indolbutírico, que é apontado como um dos maiores estimuladores de enraizamento. Desta forma, objetivou-se verificar o uso do ácido indolbutírico e do ácido giberélico associados a tempos de imersão como estimulante de brotação e enraizamento em muda pré-brotada (MPB) de cana-de-açúcar.O delineamento experimental utilizado foi inteiramente casualizado, com quatro repetições em esquema fatorial $5 \times 3$ [doses de $\operatorname{AIB}(500,1000 \mathrm{mg} \mathrm{L}-1)$, doses de GA (60 mg L-1) e doses associadas de AIB e GA $(500+60$ e $1000+60 \mathrm{mg} \mathrm{L}-1)$ e tempos de
\end{abstract} imersão $(60,120,180$ segundos)], num total de quinze tratamentos + testemunha - imersa em água destilada.A porcentagem de brotação e massa seca da parte aérea de minirrebolos de cana-de-açúcar apresentaram resultados inferiores quando comparados a testemunha. Para altura de planta, massa verde da parte aérea, massa seca da parte aérea e massa seca da raiz, a dose de 1000 mg L-1 apresentou melhores resultados em ambos. Para os parâmetros altura de planta, massa verde da parte aérea, massa seca da parte aérea e massa seca da raiz, a dose de $500 \mathrm{mg} \mathrm{L}-1$ foi inferior estatisticamente às demais. 0 uso dos reguladores de crescimento ácido indolbutírico e ácido giberélico associados aos tempos de imersão não influenciaram positivamente no crescimento dos minirrebolos de cana-de-açúcar em relação à testemunha. 


\section{INTRODUÇÃO}

A cana-de-açúcar pertence ao gênero Sacharumssp.,àfamília Poaceae (gramíneas) e ao grupo Monocotiledonea (NOVA CANA, 2013).O Brasil, atualmente, é o maior produtor mundial dessa espécie, a qual possui grande relevância para o agronegócio. No quadro nacional da cultura, Goiás tem cada vez mais destaque (CONAB, 2018).

No município de Goianésia, o cultivo da canade-açúcar iniciou-se a partir da década de 1970. Atualmente, representa uma atividade agrícola e econômica indispensável para a região, poisgera impostos eproporciona centenas de empregos (REIS, 2014). Goianésia está entre os municípios de maior destaque no setor sucroenergético, juntamente com Itumbiara e Goiatuba (QUEIROZ; FERREIRA; PAULA, 2018).

O cultivo da cana-de-açúcar é praticado de forma vegetativa, por meio de parte de plantas adultas chamadas de "toletes" ou "olhaduras"(RIBEIRO, 2017). Quando o plantio mecanizado foi adotado, as falhas durante o processo tornaram-se mais frequentes e, com isso, acarretaram prejuízos na produtividade.Devido a isso, o Programa Cana, do Instituto Agronômico de Campinas (IAC) tem buscado métodos para reduzir o volume de mudas utilizadas no plantio.

Há pouco tempo, foi desenvolvida a tecnologia de mudas pré-brotadas (MPB), a qual consiste em fazer o plantio de indivíduos já brotados no lugar de toletes. O sistema de MPB foi desenvolvido como objetivo de diminuir o volume de mudas e falhas, além de permitir maior controle na qualidade, tanto para controle de pragas e doenças quanto para uniformidade do canavial (LANDELL et al., 2012).

A utilização de mudas livres de pragas e doenças é primordial para o estabelecimento da cultura, uma vez que a mesma permanece em campo por vários anos após o plantio. Dentre as pragas de maior relevância para a qualidade das mudas, pode-se citar a broca da cana, Diatraeasaccharalis, e o besouro, Sphenophoruslevis (LANDELL et al., 2012).

O uso de mudas pré-brotadas apresenta várias vantagens: proporciona o perfilhamento mais intenso e homogêneo, evita que a resistência da camada superficial torne a emissão de perfilhos irregulares e evita interferência da profundidade de plantio (SANTI et al., 2017).

A dificuldade de enraizamento e brotaçãode algumas espécies é considerada um grande problemae pode estar relacionado a fatores da planta e do ambiente. Devido a isto, tem-se buscado técnicas auxiliares, como o uso de reguladores de crescimento, para promover maior enraizamento (BIASI, 1996), além de favorecer a brotação (ALBUQUERQUE; RODRIGUES; ALBUQUERQUE NETO, 2008).

Os reguladores de crescimento são produtos sintéticos com efeitos semelhantes aos dos hormônios vegetais, os quaissão produzidos naturalmente nas plantas, porém em baixa concentração. Esses compostos orgânicos podem modificar processos morfológicos e fisiológicos da planta (CAPUTO et al., 2008). Dentre os reguladores de crescimento, tem-se o ácido giberélico, que influencia principalmente no alongamento da parte aérea (RIBEIRO et al., 2006) e o ácido indolbutírico, queé apontado como um dos maiores estimuladores de enraizamento (FERRIANI et al., 2006).

Há dois métodos de aplicação de reguladores vegetais: o de imersão prolongada e o de imersão rápida. As auxinas podem ser aplicadas em concentrações baixas por alguns dias, ou em concentrações mais elevadas por alguns segundos ou minutos (MERCIER, 2004). Doses muito elevadas de reguladores podem inibir o desenvolvimento de gemas ou mesmo levar a morte da planta (WEAVER, 1982).Desta forma, objetivou-se verificar o uso do ácido indolbutírico e do ácido giberélico associados a tempos de imersão como 
estimulante de brotação e enraizamento em muda prébrotada (MPB) de cana-de-açúcar.

\section{MATERIAL E MÉTODOS}

O experimento foi conduzido na cidade de Goianésia-GO, no campus experimental da Faculdade Evangélica de Goianésia - FACEG, com as seguintes coordenadas geográficas: latitude 15019'03"S, longitude 49 07'02'W e altitude de 640 metros. O clima da região, segundo classificação de Köppen e Geiger, é do tipo Aw, tropical, comtemperatura média é de $24,4^{\circ} \mathrm{C}$.

$\mathrm{O}$ delineamento experimental utilizado foi o DIC (Delineamento Inteiramente Casualizado), com quatro repetições em esquema fatorial $5 \times 3$ [doses de AIB (500, $\left.1000 \mathrm{mg} \mathrm{L}^{-1}\right)$,uma dose de GA (60 $\left.\mathrm{mg} \mathrm{L}^{-1}\right)$ e doses associadas de AIB e GA $(500+60$ e $1000+60$ mg L $\left.\mathrm{L}^{-1}\right)$ e tempos de imersão (60, 120, 180 segundos)], num total de quinze tratamentos + testemunha (imersa em água destilada). Os reguladores de crescimento foram solubilizados em $60 \mathrm{ml}$ de álcool 70\% e depois em 10 litros de água, onde, posteriormente, foram imersos os minirrebolos. Cada repetição foi composta por 40 minirrebolos de cana.

Os minirrebolos, com idade entre sete e dez meses, foram cortados em campo, na Usina sucroalcooleira Jalles Machado S/A, localizada na Fazenda São Pedro Rodovia GO-080 km 75,1 zona rural de Goianésia, GO, e levados até o viveiro de produção de $\mathrm{MPB}$ na própria usina, onde foram despalhados e cortados com a máquina pneumática de fabricação própria, no tamanho de $3 \mathrm{~cm}$, com apenas uma gema cada (LANDELL et al., 2012). A variedade utilizada de cana-de-açúcar foi a CTC 9001, por apresentar em seu histórico do viveiro de MPB da Usina Jalles Machado baixa porcentagem de brotação (dados não publicados).

Os minirrebolos passaram por uma seleção, onde foram retirados aqueles com gemas danificadas ou com sinais de pragas ou doenças. Os minirrebolos escolhidos foram colocados em caixas de brotação, com dimensões de $0,30 \mathrm{~m}$ x $0,47 \mathrm{~m}$, forrada com aproximadamente $2 \mathrm{~cm}$ de substrato comercial e com a gema para cima (Figura 1). Em seguida, os minirrebolos foram cobertos novamente por mais, aproximadamente, $2 \mathrm{~cm}$ de substrato.

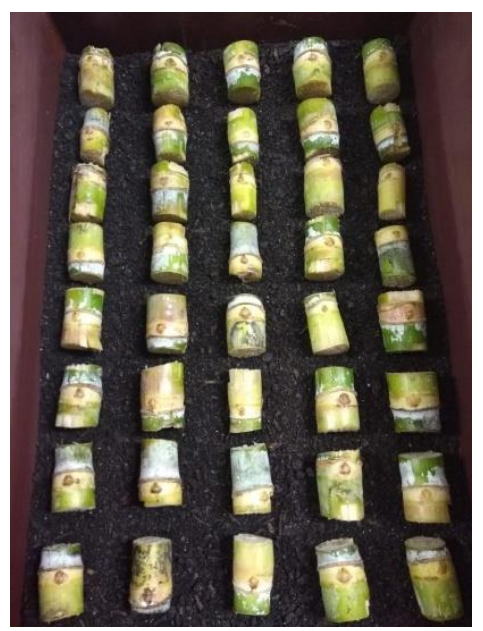

Figura 1 - Plantio de minirrebolos em caixa de brotação.

Ao terminar todas as repetições, as caixas foram posicionadas em paletes de madeira com dimensões 1,20m x 8m x 0,10 m e, em seguida, irrigadas, cada uma, com $500 \mathrm{ml}$ de água. Depois foram cobertas por lona preta, para simular uma miniestufacom o objetivo de acelerar a brotação, segundo recomendações de Landell et al. (2013) (Figura 2). 

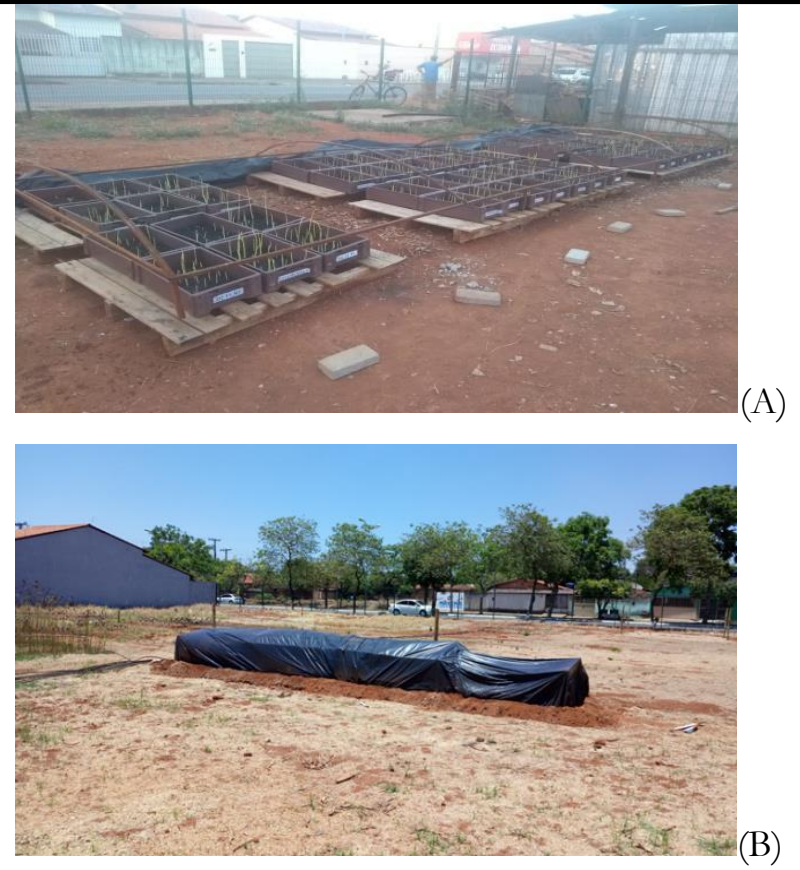

Figura 2 - Estrutura de paletes (A) e estrutura forrada com lona para simular aminiestufa (B).

As características avaliadas foram:porcentagem de brotação; número de brotações; massa verde da parte aérea; massa seca da parte aérea e massa seca da raiz. Ao fim dos quinze dias, as brotações foram cortadas rentes aos minirrebolos, medidose depois foram pesados frescos para definir a massa verde da parte aérea. Logo em seguida foram colocados em estufa a $65^{\circ} \mathrm{C}$ por 72 horas. Após esse período, as brotações foram pesadas para obter a massa seca da parte aérea.

As raízes também foram destacadas do minirrebolo, lavadas e deixadas secarem sob papel toalha por alguns minutos. Foram colocadas também em estufa a $65^{\circ} \mathrm{C}$ por 72 horas. Depois desse período de secagem, foram pesadas para obter a massa seca da raiz.

Os dados foram submetidos à análise de variância, e, após constatação de significância pelo teste F a 5\% de probabilidade as médias dos tratamentos foram comparadas entre si pelo teste de Tukey a 5\% de probabilidade. As médias dos tratamentos foram comparadas com a testemunha pelo teste de Dunnet a $5 \%$ de probabilidade.

\section{RESULTADO E DISCUSSÃO}

Observou-se diferenças significativas na fonte de variação interação doses $\mathrm{x}$ tempos de imersão para a variável massa verde da parte aérea, dessa forma, procedeu-se ao desdobramento das médias para verificar a melhor combinação dose de AIB e GA e tempo de imersão (Tabela 1). A interação doses/tempos $\mathrm{x}$ testemunha foi significativa para a variável brotação e massa seca da parte aérea. O tempo de imersão foi significativo para a variável massa seca do sistema radicular.As doses de AIB e GA foram significativas para a variável altura da planta, massa verde da parte aérea e massa seca da parte aérea e massa seca do sistema radicular.

Tabela 1 - Análise de variância das características brotação (\%), altura de planta (cm), massa seca da parte aérea (g) e da raiz (g) de minirrebolos de cana-de-açúcar (Saccharumofficinarum L.) submetidos a doses de AIB (ácido indolbutírico) e GA (ácido giberélico) em tempos de imersão.

\begin{tabular}{lcccccc}
\hline \multirow{2}{*}{ Fontes de variação } & $\begin{array}{c}\text { Grau de } \\
\text { liberdade }\end{array}$ & Brotação & Altura & $\begin{array}{c}\text { Massa verde } \\
\text { da parte aérea }\end{array}$ & $\begin{array}{c}\text { Massa seca da } \\
\text { parte aérea }\end{array}$ & $\begin{array}{c}\text { Massa } \\
\text { seca da } \\
\text { raiz }\end{array}$ \\
\hline Doses de AIB e GA & 4 & $168,83^{\text {ns }}$ & $64,09^{* *}$ & $415,83^{* *}$ & $5,61^{* *}$ & $0,82^{* *}$ \\
Tempo de imersão & 2 & $33,86^{\text {ns }}$ & $1,34^{\text {ns }}$ & $44,80^{\text {ns }}$ & $0,57^{\text {ns }}$ & $0,91^{*}$ \\
Doses X Tempo & 8 & $106,32^{\text {ns }}$ & $5,00^{\text {ns }}$ & $21,91^{*}$ & $0,25^{\text {ns }}$ & $0,17^{\text {ns }}$
\end{tabular}




\begin{tabular}{lcccccc}
\hline DT $/$ X Testemunha & 1 & $407,55^{*}$ & $0,09^{\text {ns }}$ & $288,70^{\text {ns }}$ & $4,32^{*}$ & $0,50^{\text {ns }}$ \\
\hline Tratamentos & 15 & $133,41^{\text {ns }}$ & $19,94^{*}$ & $147,79^{\text {ns }}$ & $1,99^{*}$ & $0,46^{*}$ \\
Resíduo & 48 & 91,14 & 9,95 & 89,21 & 0,90 & 0,20 \\
\hline MG & & 73,35 & 13,20 & 33,53 & 3,67 & 3,98 \\
CV\% & & 13,01 & 23,89 & 28,17 & 25,85 & 11,28 \\
\hline
\end{tabular}

$*$ significativo ao nível de $5 \%$ de probabilidade. ns não significativo. ${ }^{* *}$ significativo ao nível de $1 \%$ de probabilidade.

As doses de AIB e GA, isoladas ou em conjunto, associadas aos tempos de imersão, não proporcionaram médias estatisticamente diferentes de porcentagem de brotação quando comparadas à testemunha (Tabela 2). As médias de porcentagem de brotação com o uso da dose $500 \mathrm{mg} \mathrm{L}^{-1}$ de AIB consorciada com a dose de 60 mg $L^{-1}$ de GA no tempo de imersão de 3 minutos foi inferiorà testemunha.Dessa forma, para essa característica, não se recomenda o uso de AIB e GA nas doses avaliadas nesse experimento.

Tabela 2 - Brotação (\%) de minirrebolos de cana-de-açúcar (Saccharumofficinarum L.) submetidos a doses de AIB (ácido indolbutírico) e GA (ácido giberélico) em tempos de imersão em relação à testemunha.

\begin{tabular}{ll}
\hline Doses dos reguladores de crescimento $\left(\mathrm{mg} \mathrm{L}^{-1}\right) \mathrm{x}$ Tempo de imersão & Brotação $(\%)$ \\
\hline 500 AIB - 1 minuto & 70,00 \\
500 AIB - 2 minutos & 75,62 \\
500 AIB - 3 minutos & 65,62 \\
1000AIB- 1 minuto & 76,88 \\
1000AIB- 2 minutos & 83,25 \\
1000AIB- 3 minutos & 76,50 \\
60GA - 1 minuto & 75,00 \\
60GA - 2 minutos & 68,75 \\
60 GA - 3 minutos & 75,12 \\
500 AIB + 60 GA - 1 minuto & 75,00 \\
500 AIB + 60 GA - 2 minutos & 70,62 \\
500 AIB + 60 GA - 3 minutos & $61,88 *$ \\
1000 AIB + 60 GA - 1 minuto & 70,00 \\
1000 AIB + 60 GA - 2 minutos & 69,38 \\
T000 AIB + 60 GA - 3 minutos & 76,88 \\
Testemunha & 83,12 \\
\hline DMS & 19,88
\end{tabular}

* significativo ao nível de 5\% de probabilidade pelo teste de Dunnet.

Silva, Cato e Costa (2010) também verificavam ausência de resposta do genótipo IAC87-3396 tratado com o biorregulador a base de AIB e GA, ou seja, as médias de brotação foram estatisticamente iguais à datestemunhadurante o período de avaliação.No entanto, Loss et al. (2009) afirmaram que para a brotação das estacas herbáceas, semi-lenhosas e lenhosas de MalvaviscusarboreusCav., a concentração $6000 \mathrm{mg} \mathrm{L} \mathrm{L}^{-1}$ de AIBproporcionou maior desempenho. Estes autores destacaram queas herbáceas obtiveram resultados estatisticamente idênticos à testemunha. Faganello et al. (2015) concluíram que doses crescentes de AIB limitaram o desenvolvimento da parte aérea de Cordiatrichotoma. Os resultados encontrados nesse estudotambém são corroborados por Nienow et al. (2010) que avaliaram estacas de quaresmeira e observaram que a testemunha obteve melhor resultado para brotação, enquanto a maior dose de AIB (3000 mg $\left.\mathrm{L}^{-1}\right)$ proporcionou menores médias.

Quando se comparou os efeitos das doses dos reguladores de crescimento para a variável altura de plantas, observou-se que a dose de $500 \mathrm{mg} \mathrm{L}^{-1}$ de AIB mostrou-se inferior em relação às outras doses (Tabela 3).Provavelmente, a dose $500 \mathrm{mg} \mathrm{L}^{-1}$ de AIB não foi 
suficiente para induzir o crescimento da parte aérea do minirrebolo porque doses maiores seriam necessárias para provocar esse estímulo (LACERDA; ENÉAS FILHO; PINHEIRO, 2007). Pedroso et al. (2016) também verificaram que o uso de reguladores de crescimento a base de AIB e GA proporcionaram aumento na altura de plantas de arroz, principalmente na dose de $1000 \mathrm{mg} \mathrm{L} \mathrm{L}^{-1}$. Em trigo, o uso de biorregulador a base de AIB e GA proporcionou maior comprimento da parte aérea em plântulas (RAMPIM et al., 2012). No entanto, Lima et al. (2009) observaram que o uso de AIB causou decréscimo no desenvolvimento da altura de planta de alguns híbridos de maracujá.

Tabela 3 - Altura de plantas (cm) de minirrebolos de cana-de-açúcar (Saccharumofficinarum L.) submetidos a doses deAIB (ácido indolbutírico) e GA (ácido giberélico).

\begin{tabular}{cc}
\hline Doses dos reguladores de crescimento $\left(\mathrm{mg} \mathrm{L}^{-1}\right)$ & Altura da planta $(\mathrm{cm})$ \\
\hline $500 \mathrm{AIB}$ & $9,25 \mathrm{~b}$ \\
$1000 \mathrm{AIB}$ & $15,21 \mathrm{a}$ \\
$60 \mathrm{GA}$ & $13,55 \mathrm{a}$ \\
$500 \mathrm{AIB}+60 \mathrm{GA}$ & $13,72 \mathrm{a}$ \\
$1000 \mathrm{AIB}+60 \mathrm{GA}$ & $14,34 \mathrm{a}$ \\
\hline DMS & 3,65
\end{tabular}

Médias seguidas pela mesma letra não diferem entre si pelo teste de Tukey a 5\% de probabilidade.

Em plântulas de acácia amarela, o uso de GA na dose de $3000 \mathrm{mg} \mathrm{L}^{-1}$ apresentou melhor resultado para altura de planta (PAIXÃO et al., 2017). Diferente dos resultados encontrados por Menegaes et al. (2015), onde não houve diferença estatística entre as doses testadas de AIB em estacas de Euryopschrysanthemoides. Spassin e Garcia (2016) ao avaliarem doses de AIB em miniestacas de Eucalyptusdunnii, concluíram que a dose de $3000 \mathrm{mg} \mathrm{L}^{-1}$ proporcionou maior altura de planta, enquanto a dose de $2000 \mathrm{mg} \mathrm{L}^{-1}$ proporcionou o menor crescimento encontrado. Entretanto, os autores concluem que a aplicação de AIB não foi significativa para a altura de planta em relação à testemunha.

O estímulo ao alongamento da célula provocado pelas auxinas e giberelinasé devido aos efeitos exercidos sobre a parede celular (MERCIER, 2004). Esses efeitos decorrem da indução do aumento do fluxo de $\mathrm{H}^{+}$pela auxina, o que provoca a queda do $\mathrm{pH}$ na parede da célula e ativa a ação de enzimas expansinas. Essas enzimas quebram pontes de hidrogênio que ligam as microfibrilas de celulose e hemicelulose, as quais conferem rigidez a parede da célula. Dessa forma, ocorre o afrouxamento e aumento da extensibilidade (LACERDA; ENÉAS FILHO; PINHEIRO, 2007).

As doses isoladas de $1000 \mathrm{mg} \mathrm{L}^{-1}$ de AIB, 60mg $\mathrm{L}^{-1}$ de GA e a consorciada $1000 \mathrm{mg} \mathrm{L}^{-1}$ de AIB + 60 mg $\mathrm{L}^{-1}$ de $\mathrm{GA}$ foram eficientes no incremento das médias de massa verde da parte aérea quando comparadas à dose isolada $500 \mathrm{mg} \mathrm{L}^{-1}$ de AIB e semelhantes no efeito à dose consorciada de $500 \mathrm{mg} \mathrm{L}$ 1 de AIB + $60 \mathrm{mg} \mathrm{L}{ }^{-1}$ de GA. (Tabela 4).

Tabela 4- Massa verde da parte aérea (g) de plantas de minirrebolos de cana-de-açúcar(Saccharumofficinarum L.) submetidos a doses de AIB (ácido indolbutírico) e GA (ácido giberélico).

\begin{tabular}{cc}
\hline Doses dos reguladores de crescimento $\left(\mathrm{mg} \mathrm{L}^{-1}\right)$ & Massa verde da parte aérea $(\mathrm{g})$ \\
\hline $500 \mathrm{AIB}$ & $23,20 \mathrm{~b}$ \\
$1000 \mathrm{AIB}$ & $38,61 \mathrm{a}$ \\
$60 \mathrm{GA}$ & $34,66 \mathrm{a}$ \\
$500 \mathrm{AIB}+60 \mathrm{GA}$ & $32,57 \mathrm{ab}$
\end{tabular}




\begin{tabular}{|c|c|}
\hline $1000 \mathrm{AIB}+60 \mathrm{GA}$ & $35,88 \mathrm{a}$ \\
\hline DMS & 10,93 \\
\hline
\end{tabular}

Médias seguidas pela mesma letra não diferem entre si pelo teste de Tukey a 5\% de probabilidade.

Acredita-se que esse incremento na massa verde da parte aérea dos minirrebolos de cana-de-açúcar ocorre devido ao estímulo do crescimento do caule e das folhas pela aplicação da giberelina(LAVAGNINI et al., 2014) e do AIB, o qualinduz o alongamento de coleóptilos e seções de caule (LACERDA; ENÉAS FILHO; PINHEIRO, 2007).

Em estacas de eucalipto, o uso de AIB também proporcionou efeito vantajoso na biomassa verde da parte aérea nas doses de $2000 \mathrm{mg} \mathrm{L}^{-1}$ e $5000 \mathrm{mg} \mathrm{L}^{-1}$ (LANA et al., 2008). Ribeiro et al. (2006), ao avaliarem doses de AIB e GA emplântulas deZantedeschiaaethiopica,concluíram que o melhor resultado para massa verde da parte aérea foi com a concentração de $2 \mathrm{mg} \mathrm{L}^{-1}$ de AIB associado a $1 \mathrm{mg} \mathrm{L}^{-1}$ de GA, contudo observaram que altas doses dos fitorreguladores foram tóxicas para a planta.

Os incrementos da variável massa seca da parte aérea em relação aos tratamentos empregados foram semelhantes aos de massa verde da parte aérea. Adose isolada de $1000 \mathrm{mg} \mathrm{L}^{-1}$ de AIB e a consorciada $1000 \mathrm{mg}$ $\mathrm{L}^{-1}$ de $\mathrm{AIB}+60 \mathrm{mg} \mathrm{L}^{-1}$ de GA mostraram-se superiores na promoção de biomassa seca em relação a dose de $500 \mathrm{mg} \mathrm{L}^{-1}$ de AIB e similaresà dose de $60 \mathrm{mg} \mathrm{L}^{-1}$ de GA e a dose consorciada de $500 \mathrm{mg} \mathrm{L}^{-1}$ de AIB + 60 mg L ${ }^{-1}$ de GA.Adose de $500 \mathrm{mg} \mathrm{L}^{-1}$ de AIBtambém apresentou similaridade em relação as doses de $60 \mathrm{mg}$ $\mathrm{L}^{-1}$ de GA e a dose consorciada de $500 \mathrm{mg} \mathrm{L}^{-1}$ de AIB $+60 \mathrm{mg} \mathrm{L}^{-1}$ de GA (Tabela 5).

Tabela 5- Massa seca da parte aérea (g) de plantas de minirrebolos de cana-de-açúcar (Saccharumofficinarum L.) submetidos a doses de AIB (ácido indolbutírico) e GA (ácido giberélico).

\begin{tabular}{cc}
\hline Doses dos reguladores de crescimento $\left(\mathrm{mg} \mathrm{L}^{-1}\right)$ & Massa seca da parte aérea \\
\hline $500 \mathrm{AIB}$ & $2,63 \mathrm{~b}$ \\
$1000 \mathrm{AIB}$ & $4,49 \mathrm{a}$ \\
$60 \mathrm{GA}$ & $3,54 \mathrm{ab}$ \\
$500 \mathrm{AIB}+60 \mathrm{GA}$ & $3,44 \mathrm{ab}$ \\
$1000 \mathrm{AIB}+60 \mathrm{GA}$ & $3,91 \mathrm{a}$ \\
\hline DMS & 1,10 \\
\hline
\end{tabular}

Médias seguidas pela mesma letra não diferem entre si pelo teste de Tukey a 5\% de probabilidade.

Quando se realizou a comparação da testemunha com as doses dos reguladores de crescimento AIB e GA associados aos tempos de imersão, observou-se que a dose $500 \mathrm{mg} \mathrm{L}^{-1} \mathrm{de}$ AIB nos tempos de imersão de 2e 3 minutos proporcionoumédias demassa seca da parte aéreainferiores (Tabela 6). O uso dos reguladores de crescimento não resultou em diferenças significativas em relação à testemunha.

Tabela 6-Massa seca da parte aérea (g) de plantas de minirrebolos de cana-de-açúcar (Saccharumofficinarum L.) submetidos a doses deAIB (ácido indolbutírico) e GA (ácido giberélico)em tempos de imersão em relação a testemunha.

\begin{tabular}{|c|c|}
\hline $\begin{array}{l}\text { Doses dos reguladores de crescimento }\left(\mathrm{mg} \mathrm{L}^{-1}\right) \text { x Tempo de } \\
\text { imersão }\end{array}$ & Massa seca da parte aérea \\
\hline
\end{tabular}




\begin{tabular}{|c|c|}
\hline 500 AIB - 2 minutos & $2,68^{*}$ \\
\hline 500 AIB - 3 minutos & $2,37 *$ \\
\hline 1000AIB- 1 minuto & 4,38 \\
\hline 1000AIB- 2 minutos & 4,69 \\
\hline 1000AIB- 3 minutos & 4,41 \\
\hline 60GA - 1 minuto & 3,67 \\
\hline 60GA - 2 minutos & 3,51 \\
\hline $60 \mathrm{GA}-3$ minutos & 3,44 \\
\hline $500 \mathrm{AIB}+60 \mathrm{GA}-1$ minuto & 3,75 \\
\hline $500 \mathrm{AIB}+60 \mathrm{GA}-2$ minutos & 3,68 \\
\hline $500 \mathrm{AIB}+60 \mathrm{GA}-3$ minutos & 2,88 \\
\hline $1000 \mathrm{AIB}+60 \mathrm{GA}-1$ minuto & 4,10 \\
\hline $1000 \mathrm{AIB}+60 \mathrm{GA}-2$ minutos & 3,64 \\
\hline $1000 \mathrm{AIB}+60 \mathrm{GA}-3$ minutos & 3,98 \\
\hline Testemunha & 4,67 \\
\hline DMS & 1,98 \\
\hline
\end{tabular}

* significativo ao nível de 5\% de probabilidade pelo teste de Dunnet.

Para clones de cacau tratados com concentrações crescentes de AIB, houve aumento na biomassa dos mesmos, e as melhores doses foram $4 \mathrm{~g} \mathrm{~kg}^{-1}, 6 \mathrm{~g} \mathrm{~kg}^{-1} \mathrm{e} 8$ $\mathrm{g} \mathrm{kg}^{-1}$ (SANTOS JÚNIOR et al., 2008). Os resultados encontrados nesse estudo também são corroborados por Goulart, Xavier e Cardoso (2008), que ao avaliarem estacas de eucalipto, afirmaram que a matéria seca da parte aérea foi semelhante aos demais resultados, ou seja, a aplicação de AIB não surtiu efeito significativo nos tratamentos. Entretanto, Rampim et al. (2012) obtiveram resultados positivos para o uso de reguladores vegetais a base de AIB e GA, e os melhores resultados de massa seca da parte aérea de plantas de trigo foram obtidos com tal produto.

Para a variável massa seca das raízes, o tempo de imersão de 1 minuto mostrou-se superior na promoção do crescimento radicular em relação ao tempo de imersão de2 minutos e similar ao tempo de 3 minutos(Tabela 7).

Tabela 7- Massa seca da raiz (g) de plantas de minirrebolos de cana-de-açúcar(Saccharumofficinarum L.)em tempos de imersão no AIB (ácido indolbutírico) e GA (ácido giberélico).

\begin{tabular}{cc}
\hline Tempo de imersão & Massa seca da raiz \\
\hline 1 Minuto & $4,25 \mathrm{a}$ \\
2 Minutos & $3,85 \mathrm{~b}$ \\
3 Minutos & $3,91 \mathrm{ab}$ \\
\hline DMS & 0,34
\end{tabular}

Médias seguidas pela mesma letra não diferem entre si pelo teste de Tukey a 5\% de probabilidade.

Em relação às doses, para a variável massa seca da raiz, observou-se que ade $1000 \mathrm{mg} \mathrm{L}^{-1}$ de AIB resultou em médias superiores em relação a dose de 500 $m g \mathrm{~L}^{-1}$ de AIB e semelhante às outras doses. A dose de $500 \mathrm{mg} \mathrm{L}^{-1}$ de AIB proporcionou médias de massa seca da raizsimilares as doses de $60 \mathrm{mg} \mathrm{L}^{-1} \mathrm{de} \mathrm{GA}, 500 \mathrm{mg} \mathrm{L}-$ ${ }^{1}$ de AIB + $60 \mathrm{mg} \mathrm{L}^{-1}$ de GA e $1000 \mathrm{mg} \mathrm{L}^{-1}$ de AIB + $60 \mathrm{mg} \mathrm{L}^{-1}$ de GA (Tabela 8). 
Tabela 8- Massa seca da raiz (g) de plantas de minirrebolos de cana-de-açúcar(Saccharumofficinarum L.) submetidos adoses de AIB (ácido indolbutírico) e GA (ácido giberélico).

\begin{tabular}{cc}
\hline Doses dos reguladores de crescimento $\left(\mathrm{mg} \mathrm{L}^{-1}\right)$ & Massa seca da raiz \\
\hline $500 \mathrm{AIB}$ & $3,65 \mathrm{~b}$ \\
$1000 \mathrm{AIB}$ & $4,30 \mathrm{a}$ \\
$60 \mathrm{GA}$ & $3,83 \mathrm{ab}$ \\
$500 \mathrm{AIB}+60 \mathrm{GA}$ & $4,10 \mathrm{ab}$ \\
$1000 \mathrm{AIB}+60 \mathrm{GA}$ & $4,13 \mathrm{ab}$ \\
\hline DMS & 0,52 \\
\hline
\end{tabular}

Médias seguidas pela mesma letra não diferem entre si pelo teste de Tukey a 5\% de probabilidade.

Em estacas de bambu, o tempo de imersão de 60 segundos promoveu maior enraizamento (LIMA NETO et al., 2009). Mindêllo Neto et al. (2007) verificaram que tempos de imersão superiores a uma hora em estacas lenhosas de abacate provocaram efeito tóxico. Conforme Vieira (2011), a dose de $1000 \mathrm{mg} \mathrm{L}^{-1}$ de AIB apresentou melhor resultado no enraizamento de estacas de Tibouchinasellowiana(Cham.) Cogn., Xylopia brasiliensis Spreng. e OcoteacatharinensisMez, os quais corroboram com os encontrados nesse estudo. Para estacas de quaresmeira, não há necessidade do uso de AIB, pois este pode se tornar prejudicial para o enraizamento (NIENOW et al., 2010). De acordo com Souza (2008), o tempo de imersão de 4 minutos proporcionou maior acúmulo de massa seca da raiz em estacas de figueira. O mesmo autor conclui também que a dose de $500 \mathrm{mg} \mathrm{L}^{-1}$ no tempo de imersão de 8 minutos proporcionou maior porcentagem de enraizamento das estacas de figueira $(75 \%)$.

A auxina provoca o desenvolvimento do órgão pela indução do início da divisão celular e formação do novo meristema. Para isto, há necessidade de uma concentração de auxina um tanto elevada (MERCIER, 2004).

\section{CONCLUSÕES}

O uso dos reguladores de crescimento ácido indolbutírico e ácido giberélico associados aos tempos de imersão nãoinfluenciaram positivamente no crescimento dos minirrebolos de cana-de-açúcar em relação à testemunha.

Há poucos trabalhos que associam o AIB e GA a cultura da cana-de-açúcar como estimulante fisiológico. Poreste motivo,recomenda-se que novas pesquisas sejamrealizadaspara maiores constatações e descobertas acerca do assunto.

\section{REFERÊNCIAS BIBLIOGRÁFICAS}

ALBUQUERQUE, T. C. S.; RODRIGUES, F. M.; ALBUQUERQUE NETO, A. A. R. Efeito de bioestimulantes na brotação e enraizamento de estacas do porta-enxerto SO 4 (Vitisberlandieri X Vitis riparia). In: CONGRESSO BRASILEIRO DE FRUTICULTURA, 20.; ANNUAL MEETING OF THE INTERAMERICAN SOCIETY FOR TROPICAL HORTICULTURE, 54., 2008, Vitória. Anais... Vitória: INCAPER: Sociedade Brasileira de Fruticultura, 2008. Disponível em:<https://ainfo.cnptia.embrapa.br/digital/bi tstream/CPATSA-2009-

09/39494/1/OPB1983.pdf>. Acesso em: 15 dez. 2018.

ALVES, D. F. Doses de ethephon na produção de mudas pré-brotadas (MPB) de cana-deaçúcar. 2018. 32 f. Trabalho de Conclusão de Curso (Bacharel) Faculdade Evangélica de Goianésia, Goianésia, 2018.

BIASI, L. A. Emprego do estiolamento na propagação de plantas. Ciência Rural, Santa Maria, v. 26, n. 2, p. 309-314, 1996. Disponível em: 
<http://www.scielo.br/pdf/cr/v26n2/a25v26n

2.pdf $>$. Acesso em: 23 nov. 2018.

CAPUTO, M. M.; BEAUCLAIR, E. G. F.; SILVA, M. A.; PIEDADE, S. M. S. Respostas de genótipos de cana-de-açúcar à aplicação de indutores de maturação. Bragantia, Campinas, v. 67, n. 1, p. 15-23, 2008. Disponível

em: $<$ http://www.scielo.br/pdf/brag/v67n1/a0 2v67n1.pdf>. Acesso em: 15 dez. 2018.

CARDOSO, L. R.; VISCENSOTTI, J. M. M.; CIRINO, A. E. M.; STELUT'TI, I. M.; ZINA, A. C. S.; SALGADO, G. C.; CURSI, D. E.; PEREIRA, L. F. D.; CHAPOLA, R. G. Perfilhamento de cana-de-açúcar em função do sistema de plantio.In: XI WORKSHOP AGROENERGIA MATÉRIAS PRIMAS. 11., 2017, Ribeirão Preto. Anais... Ribeirão Preto: Centro de convenções da Cana - IAC, 2017. P. 29-34. Disponível em:<http://www.infobibos.com/Agroenergia/ CD_2017/Resumos/ResumoAgroenergia_2017 _0029.pdf>. Acesso em 29 dez. 2018.

\section{COMPANHIA NACIONAL DE} ABASTECIMENTO. Acompanhamento da safra brasileira de cana-de-açúcar, v. 5 - Safra 2018/19, n.1 - Primeiro levantamento, Brasília, p.1-63, 2018. ISSN 2318-792. Disponível em: $<$ https://www.conab.gov.br/infoagro/safras/cana>. Acesso em: 20 ago. 2018.

FAGANELLO, L. R.; DRANSKI, J. A. L.; MALAVASI, U. C.; MALAVASI, M. M. Efeito dos ácidos indolbutírico e naftalenoacético no enraizamento de estacas semilenhosas de Cordiatrichotoma (Vell.) Arrab. exSteud. Ciência Florestal, Santa Maria, v. 25, n. 4, p. 863-871, 2015. Disponível em:

$<$ http://www.scielo.br/pdf/cflo/v25n4/01039954-cflo-25-04-00863.pdf>. Acesso em: 3 jan. 2019.

FERRIANI, A. P.; BORTOLINI, M. F.; ZUFFELLATO-RIBAS, K. C.; KOEHLER, $\mathrm{H}$. S. Propagação vegetativa de estaquia de azaléia arbórea (RhododendronthomsonniHOOK. f.).

Semina: Ciências agrárias, Londrina, v. 27, n. 1, p. 35-42, 2006. Disponível em:

$<$ https://www.redalyc.org/pdf/4457/4457440

79005.pdf>. Acesso em: 28 dez. 2018.

GOULART, P. B.; XAVIER, A.; CARDOSO, N. Z. Efeito dos reguladores de crescimento AIB e ANA no enraizamento de miniestacas de clones de EucalyptusgrandisxEucalyptusurophylla. Revista
Árvore, Viçosa, v. 32, n. 6, p. 1051-1058, 2008.

Disponível em:

<http://www.scielo.br/pdf/rarv/v32n6/a10v3

2n6.pdf>. Acesso em: 28 dez. 2018.

LACERDA, C. F.; ENÉAS FILHO, J.; PINHEIRO,

C. B. Fisiologia Vegetal. Fortaleza:

Departamento de Bioquímica e Biologia Molecular, Universidade Federal do Ceará, 2007. Disponível em:

$<$ http://www.fisiologiavegetal.ufc.br/APOSTI

LA/REGULADORES.pdf $>$. Acesso em: 15 jan. 2019.

LANA, R. M. Q.; LANA, A. M. Q.; BARREIRA, S.; MORAIS, T. R.; FARIA, M. V. Doses de ácido indolbutírico no enraizamento e crescimento de estacas de eucalipto (Eucalyptusurophylla).

BioscienceJournal, Uberlândia, v. 24, n. 3, p. 13-18, 2008. Disponível em:

$<$ http://www.seer.ufu.br/index.php/bioscienc ejournal/article/view/6708/4419>. Acesso em: 25 dez. 2018.

LANDELL, M.G. de A.; CAMPANA, M.P.; FIGUEIREDO, P.; XAVIER, M.A.; ANJOS, I.A. dos; DINARDO-MIRANDA, L.L.; SCARPARI, M.S.; GARCIA, J.C.; BIDÓIA, M.A.P.; SILVA, D.N. da; MENDONÇA, J.R. de; KANTHACK, R.A.D.; CAMPOS, M.F. de; BRANCALIÃO, S.R.; PETRI, R.H.; MIGUEL P.E.M. Sistema de multiplicação de cana-de-açúcar com uso de mudas pré-brotadas (MPB), oriundas de gemas individualizadas. Instituto Agronômico de Campinas, 2012. 22p. (IAC. Documentos, 109).Disponível em:

$<$ http://www.udop.com.br/ebiblio/pagina/arq uivos/2013_sistema_multiplicacao_cana_com_ mudas_pre_brotadas.pdf $>$. Acesso em: 15 mar. 2018.

LAVAGNINI, C.G.; DI CARNE, C.A.V.; CORREA, F.; HENRIQUE, F.; TOKUMO, L.E.; SILVA, M. H.; SANTOS,P.C.S. Fisiologia Vegetal Hormônio Giberelina. Revista Científica Eletrônica de Agronomia, Garça, v.25, n.1, p.48-52, 2014. Disponível em: $<$ http://faef.revista.inf.br/imagens_arquivos/a rquivos_destaque/bhVGBiNA87kYjIU_20147-1-21-4-1.pdf>. Acesso em: 17 jan. 2019.

LIMA NETO, M. C.; RIBEIRO, J. S.; BEZERRA NETO, E. Enraizamento de estacas de bambu com o uso de auxinas. Revista Acadêmica Ciências Agrárias e Ambiental, v. 7, n. 2, p. 17579, 2009. Disponível em:

$<$ https://periodicos.pucpr.br/index.php/cienci 
aanimal/article/view/9864/9321>. Acesso em: 19 out. 2018.

LIMA, C. A.; JUNQUEIRA, N. T. V.; SOUZA, L. S.; BELLON,G.; BRANCO, M. T. C.; JUNQUEIRA, K. P.; SANTOS, E. C. Enraizamento de híbridos interespecíficos de maracujá utilizando regulador de crescimento AIB (ácido indolbutírico). In: IV ENCONTRO DE JOVENS TALENTOS DA EMBRAPA CERRADOS, 4., 2009, Planaltina. Resumos... Planaltina: EMBRAPA CERRADOS, 2009, p. 157-158. Disponível em:

<https://ainfo.cnptia.embrapa.br/digital/bitstr eam/CPAC-2010/31347/1/doc-243.pdf >.

Acesso em: 28 dez. 2018.

LOSS, A.; TEIXEIRA, M. B.; SANTOS, T. J.; GOMES, V. M.; QUEIROZ, L. H. Indução do enraizamento em estacas de Malvaviscusarboreus Cav. com diferentes concentrações de ácido indol-butírico (AIB). Acta Scientiarum - Agronomy, Maringá, v. 31, n. 2, p. 269-273, 2009. Disponível em: <http://www.scielo.br/pdf/asagr/v31n2/v31n 2a13.pdf>. Acesso em: 27 dez. 2018.

MENEGAES, J. F.; BACKES, F. A. A. L.; BELLÉ, R. A.; PERES, T. E. S. Enraizamento de estacas de Euryopschrysanthemoides (DC.) B. Nord. em vaso. Ornamental Horticulture, Campinas, v. 21, n. 3, p. 382-386, 2015. Disponível em: $<$ https://ornamentalhorticulture.emnuvens.co $\mathrm{m} . \mathrm{br} / \mathrm{rbho} /$ article/viewFile/732/610>. Acesso em: 18 jan. 2019.

MERCIER, H. Auxinas. In: KERBAURY, G. B.

Fisiologia Vegetal. Rio de Janeiro: ed. Guanabara Koogan S. A. 2004. cap. 8, p. 217249. Disponível em:

<http://www.eno16.com/morfo_fisio/adicion ais $/$ Livro $\% 20$ Fisiologia $\% 20$ Vegetal $\% 20$ \%20Kerbauy.pdf>. Acesso em 25 dez. 2018.

MINDÊLLO NETO, U. R.; TELLES, C. A.; BIASI, L. A.; PETERS, E. Enraizamento de estacas herbáceas do abacateiro 'Fuerte' com diferentes períodos de imersão em solução de ácido indolbutírico. Acta ScientiarumAgronomy, Maringá v. 29, n. 3, p. 387-390, 2007.

Disponível em:

<https://www.researchgate.net/publication/24 0828809_Enraizamento_de_estacas_herbaceas_ do_abacateiro_'Fuerte'_com_diferentes_period os_de_imersao_em_solucao_de_acido_indolbut irico_-_DOI_104025actasciagronv29i3389>.

Acesso em: 19 out. 2018.
NIENOW, A. A.; CHURA, G.; PETRY, C.; COSTA, C. Enraizamento de estacas de quaresmeira em duas épocas e concentrações de ácido indolbutírico. Revista Brasileira de Agrociência, Pelotas, v. 16, n. 1-4, p. 139-142, 2010. Disponível em:

$<$ https://periodicos.ufpel.edu.br/ojs2/index.ph p/CAST/article/view/2022/1859>. Acesso em: 27 dez. 2018.

NOVA CANA.Expectativa $\mathbf{X}$ realidade: $\mathbf{o}$ avanço da mudas pré-brotadas nos canaviaisdo Brasil, fev. 2013. Disponível em: <https://www.novacana.com/cana-deacucar>. Acesso em: 29 dezemrbo 2018.

PAIXÃO, M. V. S.; LIMA, M. G. B.; BOZETTI, M.; FARIA JÚNIOR, H. P.; PAIXÃO, P. P. Superação de dormência das sementes e desenvolvimento de plântulas de acácia amarela (Cassia ferrugínea (Schrad) Schradex DC).

Pesquisa Agropecuária Gaúcha, Porto Alegre, v. 23, n. 1-2, p. 22-30, 2017. Disponível em:

<http://www.revistapag.fepagro.rs.gov.br/files /PAG23article3.pdf>. Acesso em: 29 dez. 2018.

PEDROSO, L.; BERTOLDO, J. L.; MARCHI, B. A.; CRUZ, R. M. S.; SOUZA, B. C.; LERMEN, C.; ALBERTON, O. Avaliação dos fitorreguladores auxina e giberelina na germinação e crescimento do arroz. Arquivos de Ciências Veterinárias e Zoologia, Umuarama, v. 19, n. 4, p. 241-245, 2016. Disponível em:

<http://www.revistas.unipar.br/index.php/vet erinaria/article/viewFile/6103/3421>. Acesso em: 17 jan. 2019.

QUEIROZ, A. M.; FERREIRA, J. B.; PAULA, J. S. A.O setor sucroalcooleiro e o valor da terra agrícola em Goiás e em Minas Gerais: uma análise econométrica. Estudo

\&Debate,Lajeado, v. 25, n. 1, p. 86-107, 2018. Disponível em:

<http://www.univates.br/revistas/index.php/e studoedebate/article/view/1408/1297>. Acesso em: 29 out. 2018.

RAMPIM, L.; COSTA, A. C. P. R.; NACKE H.; KLEIN, J.; GUIMARÃES, V. F. Qualidade fisiológica de sementes de três cultivares de trigo submetidas a inoculação e diferentes tratamentos. Revista Brasileira de Sementes, Londrina, v. 34, n. 4, p. 678-685, 2012.

Disponível em:

<http://www.scielo.br/pdf/rbs/v34n4/20.pdf >. Acesso em: 29 nov. 2018. 
REIS, M. A. A expansão da cultura canavieira e o crescimento econômicono município de Goianésia - Goiás. 2014. 85 f. Tese (Mestrado em Desenvolvimento Regional)-Faculdades Alves Faria, Centro Universitário Alves Faria, Goiânia, 2014. Disponível em:

$<$ http://webcache.googleusercontent.com/sear ch?q= cache:DwygiF23c3YJ:www.unialfa.com.b r/lib/download.php\%3Farq\%3Darqs/bibliotec a/digital/73.pdf $\% 26$ nome $\% 3 \mathrm{Da}$-expanso-dacultura-canavieira-e-o-crescimento-econmicono-municpio-de-goiansia---

gois.pdf $+\& c d=3 \& h l=p t-B R \& c t=c \ln k \& g l=b r>$. Acesso em: 17 jan. 2019.

RIBEIRO, M. N. O.; PASQUAL, M.; VILLA, F.; ALBUQUERQUE, K. S. Efeitos do AIB e $\mathrm{GA}_{3}$ na micropropagação de Zantedeschiaaethiopica. Revista Ceres, Viçosa, v. 53, n. 309, p. 568-573, 2006. Disponível em: <http://www.ceres.ufv.br/ojs/index.php/ceres /article/view/3183/1075>. Acesso em: 06 jan. 2019.

RIBEIRO, M. P. C. A geografia da cana-de-açúcar. IBGE, Coordenação de Geografia, Rio de Janeiro, 2017, 172p. Disponível em:<https://biblioteca.ibge.gov.br/visualizacao /livros/liv101436.pdf>. Acesso em 23 dez. 2018.

SANTI, P. H. P.; SCAVAZZA, A. L.; SOARES, M. R.; CASAGRANDE, J. C.; GAZAFFI, R.; BELLONI, A. L.; SANTANA, C. A.; ROCHA, K. S. S.; LAVORENTI, J. A. L.; GONÇALVES, R. S.; BORELLI, L. M.; CAMPASSI, J. C.; MORAES, G. B.; NYSSEN, D.; DOMINGOS; A. R.; LANÇONI, R.; SIMIONE, J. R.; FERREIRA, J. A.;

SANTOS JÚNIOR, A. J.; ALMEIDA, A. A. F.; SILVA, D. C.; FARIA, J. C.; MIELK, M. S.; GOMES, F. P. Enraizamento de estacas, crescimento e respostas anatômicas de mudas clonais de cacaueiro ao ácido indol-3-butírico.

Revista Brasileira de Fruticultura, Jaboticabal, v. 30, n. 4, p. 1071-1082, 2008. Disponível em: <http://www.scielo.br/pdf/rbf/v30n4/a38v30 n4.pdf $>$. Acesso em: 03 jan. 2019.

SILVA, M. C.; CATO, S. C.; COSTA, A. G. F. Produtividade e qualidade tecnológica da soqueira de cana-de-açúcar submetida a aplicação de biorreguladores e fertilizantes líquidos. Ciência Rural, Santa Maria, v. 40, n. 4, p. 774-780, 2010.Disponível em: <http://www.scielo.br/pdf/cr/v40n4/a541cr2 287.pdf>. Acesso em 30 dez. 2018.

SOUZA, C. S. S. Estudo de ambientes de enraizamento, tempo de imersão em AIB, estratificação a frio e enxertia de mesa na figueira. 2008. $101 \mathrm{f}$. Tese (Doutorado) Universidade Estadual Paulista, Faculdade de engenharia de Ilha Solteira, Ilha Solteira, 2008. Disponível em:

<https://repositorio.unesp.br/bitstream/handl e/11449/106209/souza_css_dr_ilha.pdf?seque nce $=1>$. Acesso em: 17 jan. 2019.

SPASSIN, A. C.; GARCIA, F. A. O. Ácido indolbutírico (IBA) é viável para a sobrevivência e o enraizamento de miniestacas de Eucalyptusdunnit?.Enciclopédia Biosfera, Goiânia, v. 13, n. 23, p. 829-841, 2016.

Disponível em:

<http://www.conhecer.org.br/enciclop/2016a /agrarias/o\%20acido.pdf $>$. Acesso em: 18 jan. 2019.

VIEIRA, D. P. Efeito do ácido indolbutírico (AIB) e cinetina no enraizamento de estacas em Tibouchinasellowiana(Cham.) Cogn., XylopiabrasilienisSpreng. e OcoteacatharinensisMez. 2011. 45 f.

Trabalho de Conclusão de curso(Bacharel em Ciências Biológicas) - Universidade do Extremo Sul Catarinense, UNESC, Criciúma, 2011. Disponível em: <http:/ / repositorio.unesc.net/bitstream/1/449 /1/Daiane $\% 20$ Pedroso $\% 20$ Vieira.pdf $>$. Acesso em: 06 jan. 2019.

WEAVER, R. J.; Reguladores del crescimento em laagriculture. 2. ed. Barcelona, Barcelona, 1982. 540 p. 